\title{
Incision-induced Bleeding Method
}

National Cancer Institute

\section{Source}

National Cancer Institute. Incision-induced Bleeding Method. NCI Thesaurus. Code C122039.

Any of multiple methods used to assess bleeding time, in which a controlled incision is made in the dermis and clotting time is measured. 